\title{
Systematic proposal for UX centered mobile apps for tracking performance in sports through an application in recreational surfing
}

\author{
Raoni Pontes Casellia, Marcelo Gitirana Gomes Ferreira ${ }^{b}$ \\ aniversidade Federal de Santa Catarina - UFSC \\ UUniversidade do Estado de Santa Catarina - UDESC \\ e-mails: raonicaselli@gmail.com; marcelo.gitirana@gmail.com
}

\begin{abstract}
The purpose of this article is to propose a systematic for mobile apps used to track performance during the practice of sports, applying it to recreational surfing, through the user-centered design process for developers and companies to develop products that achieve their goal providing a positive user experience. This research was based on a systematic review of literature on UX Design, User-Centered Design and in tools with the greatest potential to be used to measure performance during the sports practice, such as GPS, accelerometer and gyroscope to measure the physiological variables involved. The results show the use of the systematic in a mobile app for recreational surfing, detailing the design process applied in a system composed of the app and a device used to capture data from the sports practice. The systematic was positively evaluated to guide the development of mobile apps for surfing and other sports that share the outlined physiological variables.
\end{abstract}

Keywords: user experience, user-centered design, performance in sports, mobile apps, recreational surfing.

\section{Introduction}

The tracking of sports performance benefited from a period of accelerated technological development, stimulated by a highly competitive market and technological research projects being financed worldwide (MYERS, 1998). One example is data tracking devices that use Global Positioning System (GPS) technologies and inertial sensors such as accelerometer, gyroscope, barometer, magnetometer and compass to collect data, providing information on the performance and body health during physical activity through a mobile app (AHTINEN et al., 2008; GUO et al., 2013; OH; LEE, 2015).

One area that contributes to the development of interactive hardware and software products is UX Design. Its main objective is to analyze how users perceive and interact physically and emotionally with products, services and objects to improve their overall experience (LAW et al., 2009; ROTO et al., 2011).

There are still few solutions of these kind of products available in the market that actually work well. This is mainly due to the high cost of developing the hardware (GPS device and sensors) and software responsible for collecting and analyzing the data collected by the sensors, and the complexity of presenting them in a user-friendly way (GUO et al., 2013; SAHAR et al., 2014; CASELLI, 2015; OH; LEE, 2015). The use of the User-Centered
Design (UCD) process to propose a systematic approach to sports performance tracking mobile apps that encompass aspects of user experience in the context of recreational practice is adequate, since one of the principles of the user-centered approach is the consideration of user experience (INTERNATIONAL..., 2010).

This research sought to propose a systematic for sports performance tracking mobile apps from the perspective of the user experience, to measure the performance of the practitioner of recreational sports activities, making him more competitive and improving his experience of use, through the following specific objectives: identify tools and techniques recommended to measure the performance of recreational athletes; UX aspects in sports; apply the systematic in the development of an app for the tracking of the performance of recreational surfers; and evaluate the systematic and its application with experts in mobile app development.

\section{UX Design in sports}

In sports, UX Design has been widely used in the development of products such as smartwatches and also services, through mobile apps and websites (AHTINEN et al., 2008; PILLONI et al., 2013; SAHAR et al., 2014). Many sportswear companies, such as Nike (DIAS, 2014), have created a context of use that involves more than one type of 
user interaction, such as the relationship between data tracking devices and mobile apps. In the first, a physical interface with basic functions is used to start and end data collection, while in the second there is a graphical user interface (GUI), allowing the users to see the processed data in a language easy to understand. To develop a good product or service related to sports, it is necessary to study the motivations and needs of the user throughout the practice, since these reveal the opportunities of UX improvements (NYLANDER; THOLANDER, 2014; AZEVEDO et al., 2017).

For a general understanding, it is possible to separate the phases of sports research in four time intervals indicated by Roto et al. (2011): before use, during use, after use and over time, according to Figure 1. The mentalization of the experience happens during the preparation for the activity, anticipating emotions and conflicts, while the equipment to be used is being setup and the place of practice chosen. Then during the practice, the main physical, emotional and social interactions take place. At the conclusion of the activity, the equipment used is stored and the practitioner leaves the place of practice, ending with a reflection on the experience some time after its conclusion. With the accumulation of practices new actions arise from the motivated user, such as the introduction of training, stretching and warm-ups to assist in the sports practice, performance tracking, consolidation of techniques, emergence of preferences for specific aspects of the practice. This happens in the long term, after accumulating some experiences in the activity and begins with reflections on

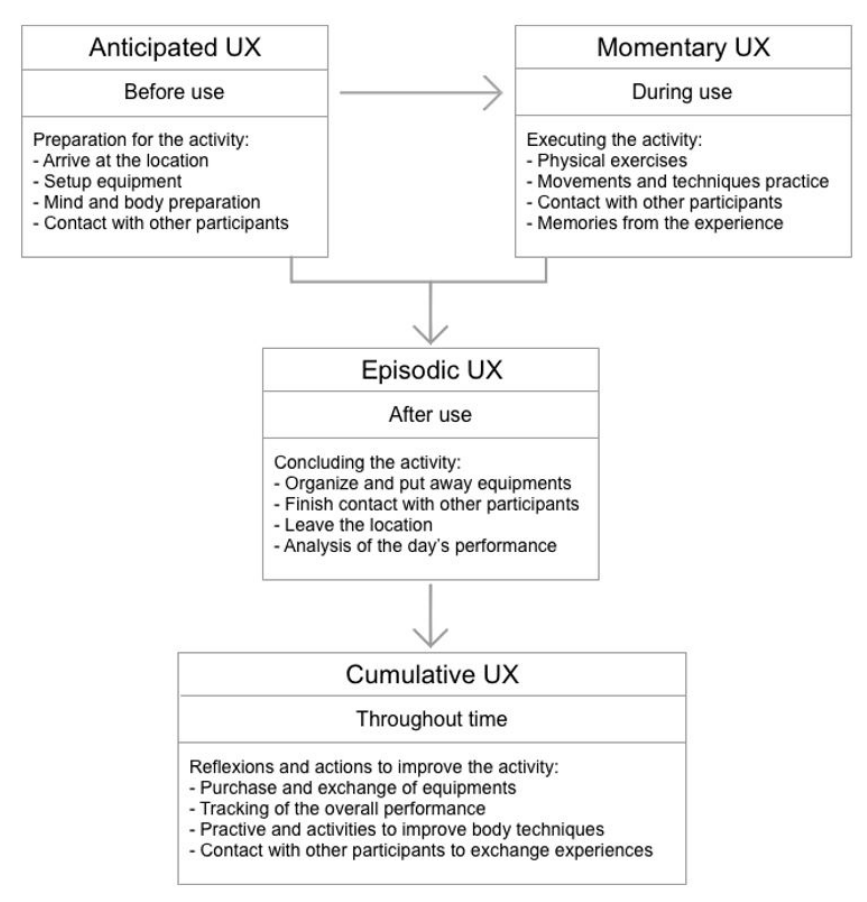

Figure 1. User experience time intervals in sports. Source: Elaborated by the author. the motivations and measures necessary to increase the efficiency and satisfaction in the sports practice.

Cumulative UX is valuable for the user experience design. Researches point to the importance of thinking about UX in the long term, proposing a method to measure the dynamics of user experience over time by promoting an understanding of how design attributes interact with contextual details in certain contexts and can inspire design (KARAPANOS et al., 2010). Longitudinal and retrospective studies (VARSALUOMA; SAHAR, 2014) suggest that the UX evaluation in the long term can help in the verification of UX practitioners' expectations, future work planning, understanding UX changes, future product development and updating current digital products.

\section{User-centered design process}

In order to develop products, services and information systems considering the UX, one of the best known processes is the UCD, described in ISO 9241-210. It's principles are: explicit understanding of users, tasks and environments; user involvement in the entire design and development; user-centered assessment; interactive process; full consideration of user experience; and adoption of multidisciplinary skills and perspectives (INTERNATIONAL..., 2010). It aims to ensure that the product meets the needs of the user for which it was designed, being usable and understandable, in order to design the product to serve him (KOBAR, 2014). The UCD is composed of several methods and tasks, which are used according to information about the type of product, its requirements, team, deadlines and the environment in which it is being developed (U.S. DEPARTMENT..., 2017).

A complete design process comprises different phases in a linear (cascade model) or cyclic (agile model) software development project. Different processes of UCD or UX Design are seen in the literature, each with its own phases, nomenclatures, tools and goals. Despite this diversity, they all follow a similar logic with some authors using three phases to describe this process (BROWN, 2009; GABRIEL-PETIT, 2010), while others use four (HARTSON; PYLA, 2012; US DEPARTMENT..., 2017) and up to five phases (HENRY; THORP, 2008; UX MASTERY, 2012; KOBAR, 2014). It always begins understanding the problem and context, ending the phase with a list of requirements that guide the next one, where concepts for solving the problem will be elaborated with low and high fidelity prototypes. During this and the following phase, a cyclical process of design and evaluation is initiated to arrive at the best solution to the problem, resulting in the implementation of a specified and validated prototype with the users, in order to reach a commercially viable and sustainable product. 


\section{Methodology}

This research was divided into three parts, beginning with the use of the UCD to propose a systematic for sports performance tracking mobile apps. Afterwards, the systematic was applied in the case of recreational surfing, putting into practice tools and techniques of each phase of the design process in the development project of a mobile app. Finally, the systematic and its application were evaluated by mobile app experts regarding their applicability and contribution to the environment.

The construction of this systematics was based on a literature review and analysis of the models of the referenced authors. From the recommendations of activities, tools and techniques suggested by the literature for the design of products and services, a systematic was proposed based on the UCD. An application of the systematic was conducted in recreational surfing to demonstrate its practicality in the development of a mobile app project of an adventure sport in nature. The use of techniques and tools presented in the systematic allowed a development centered on the user experience.

The proposed evaluation considered the contribution and practical applicability of the systematic by five professional experts in fields that contribute to the development of apps in the area of sports with experience in recreational surfing, selected by means of a non-probabilistic sampling for convenience, being chosen the members of the population that were accessible (SCHIFFMAN; KANUK, 2000). From the selection of the sample, the application of the developed systematic was presented through slideshow to the evaluators collecting data using an electronic questionnaire, with closed questions related to the contribution, applicability and structuring of the app, in the Likert type scale format with an open question for comments. The collected data was compiled and treated using descriptive statistics.

\section{Systematic proposal for sports performance tracking mobile apps}

The proposal followed the references of the reviewed literature, being adapted for the development of sports performance mobile apps. A survey of the UCD process models for the development of products, services and information systems was carried out, identifying seven different models in the literature, ranging from UX Design, UCD and Design Thinking processes, all focused on the user experience (HENRY; THORP, 2008; BROWN, 2009; GABRIEL-PETIT, 2010; HARTSON; PYLA, 2012; KOBAR, 2014; U.S. DEPARTMENT..., 2017).

The phases of each model, although presenting different nomenclatures, have similar proposals of activities and tools. This research followed the nomenclature and division of phases in the model proposed by Gabriel-Petit (2010), which uses more common terms among the different models and has a process widely described and explained, with high technical quality. In this model, the phases are called Discovery, Design and Development. A review of the activities, tools and techniques was carried out for each of the phases of the design process, comparing the identified models and selecting the most used ones (GABRIEL-PETIT, 2010).

The proposal of this systematic consists in the compilation of the activities of each one of the presented phases and the recommendation of tools and techniques for its execution. The tools and techniques selected are present in most of the analyzed models, with at least four using them in their process. Through the combination of the UCD process and the importance of sports practice as a representation of the total user experience through the use of a performance tracking system, the systematics represented in Figure 2 was proposed.

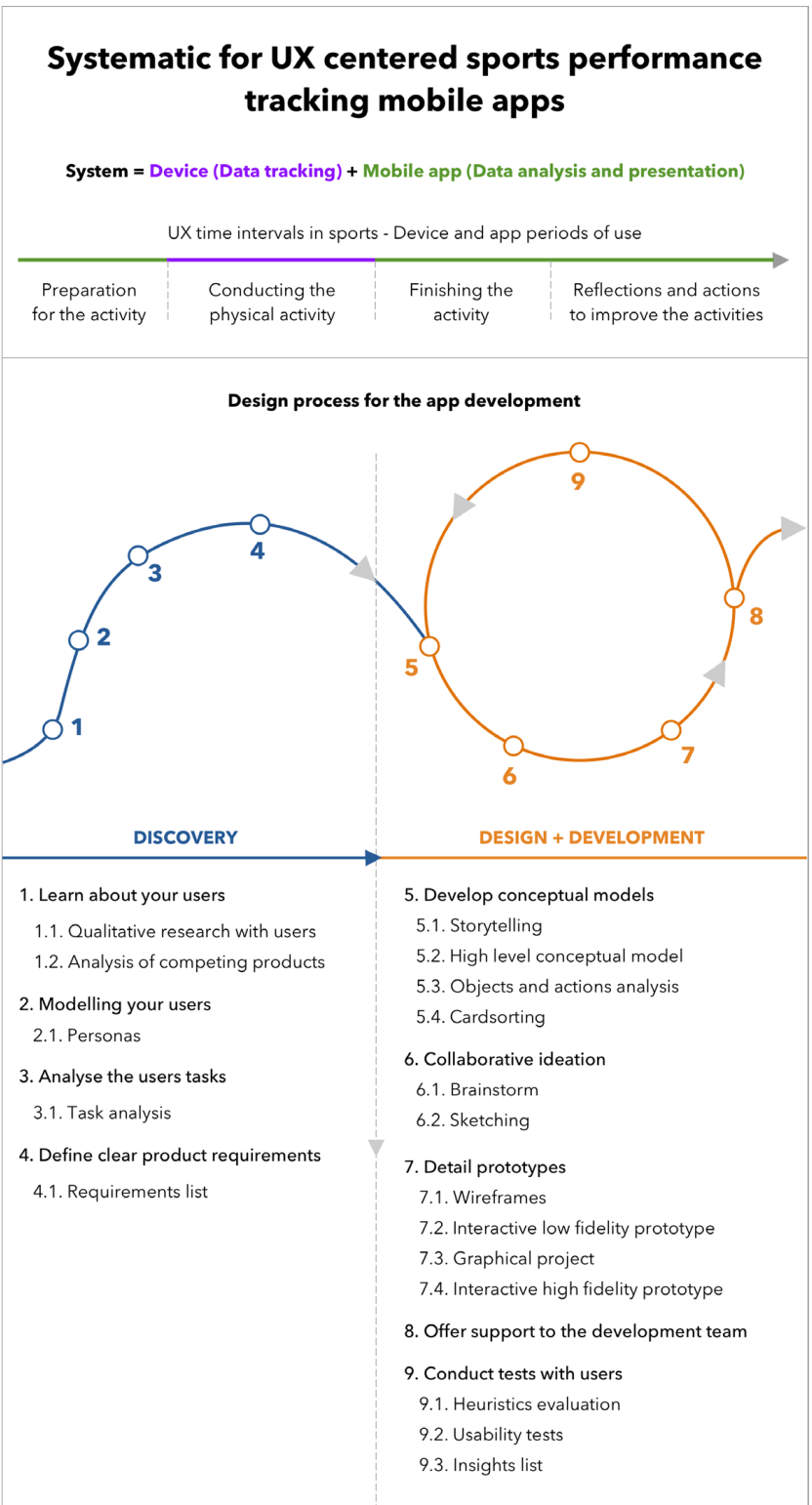

Figure 2. Systematic for UX centered sports performance tracking mobile apps. Source: Elaborated by the author. 
This systematic presents the different phases of the UCD process in a linear way, so that the process has an initial, intermediate and final phase, even though the design and development phases can be repeated. The information collected during the discovery phase is used as the basis for the product development, so if changes are observed in the market, context of product use, target audience or technological advance that alter the foundation of the product design, it would be necessary to return to this phase to identify which changes occurred. After the diagnosis, identifying its repercussion in the implementation, actions should be taken to solve the problem, either restarting or just adjusting the current project.

The Design and Development phases form a cycle of continuous improvement through the conduction of experiments that seek to identify the best way to solve the pains and needs of users. These experiments begin by defining assumptions about how the development team believes users would use certain feature, testing their usability and value through prototypes in usability tests. These help the team identify which assumptions were validated or not, returning to the Design phase to refine the solution and restart the cycle. This process can continue to occur indefinitely, following the product life cycle. The user experience evolves over time along with the demand for new features, while old features become basic product items, decreasing their added value with frequent use.

The proposed systematic suggests the main tools and techniques of each phase, helping in the development of this type of app by simplifying and expediting the search for resources and ways to solve the problems encountered during this process.

\section{Application of the systematic in a mobile app for recreational surfing}

The systematic application aimed to put into practice the tools and techniques highlighted by performing the activities of each phase in the development of a recreational surfing mobile app to improve the performance of the practitioner. For the application, the steps of the UCD process were followed using the context of the recreational surfing practice, according to the systematic - Discovery, Design and Development. The app structure and the information architecture were defined, without developing a high-fidelity prototype, taking into consideration that each company has its own requirements according to its specific visual identity. Thus, the application was carried out only until the activity of ideation in the Design phase, characterized by the elaboration of wireframes or low-fidelity prototypes of the app. The Development phase was not applied, not being possible to exemplify an interactive cycle of improvement.

\subsection{Discovery phase}

In this phase, during the activity of learning about the users, qualitative research and analysis of competing products were carried out; the creation of personas in the activity of users modelling; task analysis in the activity of analyzing the users tasks; and the definition of business, market, user and technical requirements in the activity of choosing clear product requirements. For the qualitative research, a questionnaire was created and distributed online, with the goal of discovering who is the target audience of the app through demographic characterization and knowledge about surfing. The online form was sent to various social networking groups in Facebook with surfers from Florianópolis/SC and other regions in Brazil. 42 responses were obtained for analysis and the data was used to create personas, user requirements and to develop the task analysis.

For the analysis of competing products, a Google search was performed seeking companies that own this type of product and a search in the app stores to find the main companies, analyzing the comments and evaluations left by users. From the collected data, the main features, objectives, negative and positive points for each product and mobile apps were tabulated. The creation of personas was based on the users profiles, collected in the qualitative research, analyzing the answers of the questionnaire and categorizing in two more common public profiles. For the task analysis, the same table developed in the analysis of competing products was used, separating the main features that the app should have (that adds more value to users) and described what each task should solve of problems for the users. The requirements were defined based on the qualitative research, the personas, the analysis of competing products and the task analysis. In addition, guiding questions presented by Gabriel-Petit (2010) were used to support the definition of product requirements.

\subsection{Design phase}

In the design phase, composed by the activities developing conceptual models, devising and detailing, the following tools and techniques were used: storytelling; high-level conceptual model; analysis of objects or actions; cardsorting; ideas generation, refinement and selection. For the storytelling, the resulting personas and task analysis were used for the story's main characters and features. A day in the life of the character was created, describing the use of the app in various situations that fit the context of UX (before use, during use and after use), with the intention to identify problems and exemplify the context of use, generating important results for the creation of the interactions. 
The conceptual model was based on the results of the task analysis and storytelling, describing in details how the app works, reflecting about the use described in the storytelling and how the features should work in the app architecture. Therefore, the conceptual model expanded the results of the task analysis in the context of the UX, creating a guide for generating user interaction ideas. The analysis of objects and actions was based on the results of the conceptual model and storytelling to predict the elements of user interaction required to perform the tasks. The objects are related to the actions and are suggested considering the type of content involved and the form of use, if it's an input or consumption of data, a navigational or structural element, deriving information from the conceptual model.

The cardsorting was applied in a session with five participants, part of the target audience. The terms related to the context (waves, winds and ocean bottoms), practitioner (surfer position on the board, fundamentals and maneuvers) and tasks (session, forecast, report, profile and settings) were used. All terms were written on small cards and each participant categorized them into groups, relating them to each other. This allowed the creation of relationships between texts and labels and understanding of the language more common to users. After these activities, ideas were generated and refined using the brainstorm creativity technique, ending with a selection through a multicriteria matrix. Figures 3, 4 and 5 shows the selected ideas drawn in wireframes.

The first screen shows the proposal for the main navigation, with the main features in a lower navigation bar: Surf feed, Find Waves, Performance, Social and/or Notifications and More (Profile, Settings). The suggested header consists on the title of the screen and a main action such as: Add surf session, Add wave report or Add beach.
The main content of the screen is in the middle, with a internal scroll bar. The second screen shows the Surf feed feature, which is a timeline of Reports and Sessions published by the user or others, in order to be a space for content consumption and social interaction. The third screen shows the Performance feature, divided into two parts, the first shows a graph or performance data of all sessions published by the user, with a filter of data type (duration, distance traveled, speed of surfing and/or rowing) and quantity (total, average). The user could also have the option to select the time interval of the sessions (all sessions or within a specific date range).

The idea shown above is to show the user a list of beaches that have published reports and wave forecast, with a filter to facilitate discovery. One option would be to allow the list to be viewed on an interactive map, with the same data as the beaches. Each beach can show a summary of the forecast and the number of reports published to facilitate the scan. The second screen shows the individual screen of the beaches, where the user has access to the reports published on this beach and also the waves forecast. The third screen is an example of the user adding their own report, where he has to input which beach he is in, weather data that can be observed, an option to add media (photos or videos) and the button to publish the report.

The main feature that was worked on was the Surf Session, which starts its flow after the user clicks on the action button in the app header. The first screen shows an introductory text and two input options that the user can select: synchronize with device or add session from his memory. The second option leads to a screen similar to the Add Beach Report screen, with the difference of the user adding data related to the surf session and giving a score of 1 to 5 (represented by the stars). This option could also
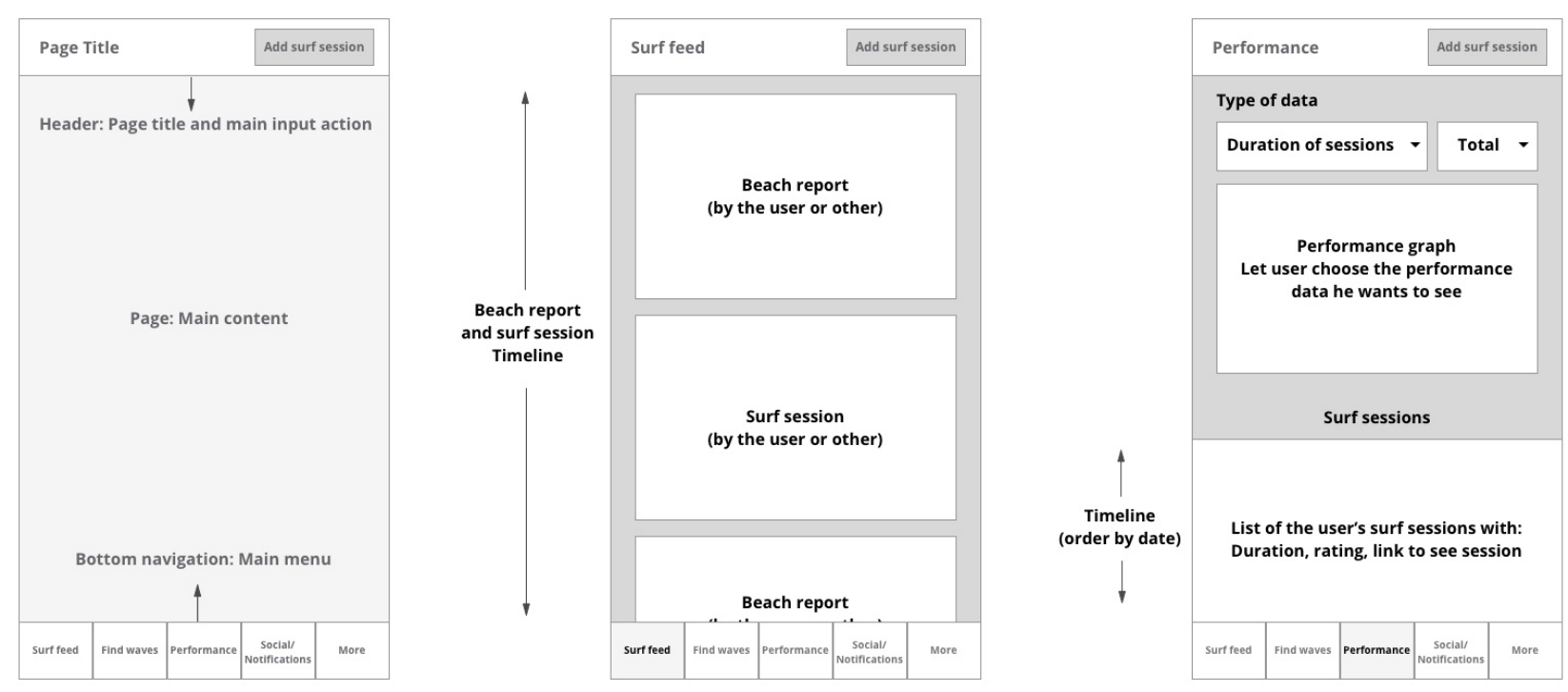

Figure 3. Main navigation, surf feed and performance. Source: Elaborated by the author. 


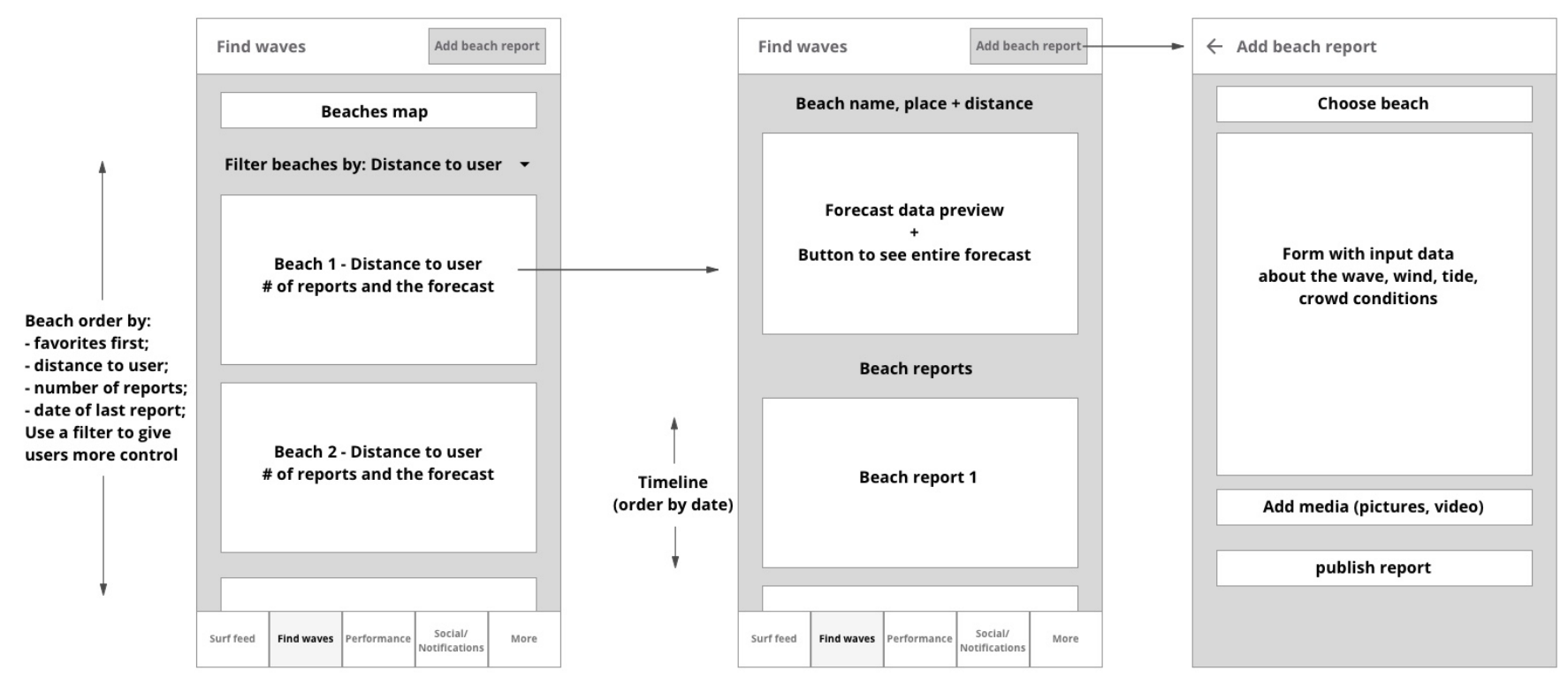

Figure 4. Find waves. Source: Elaborated by the author.

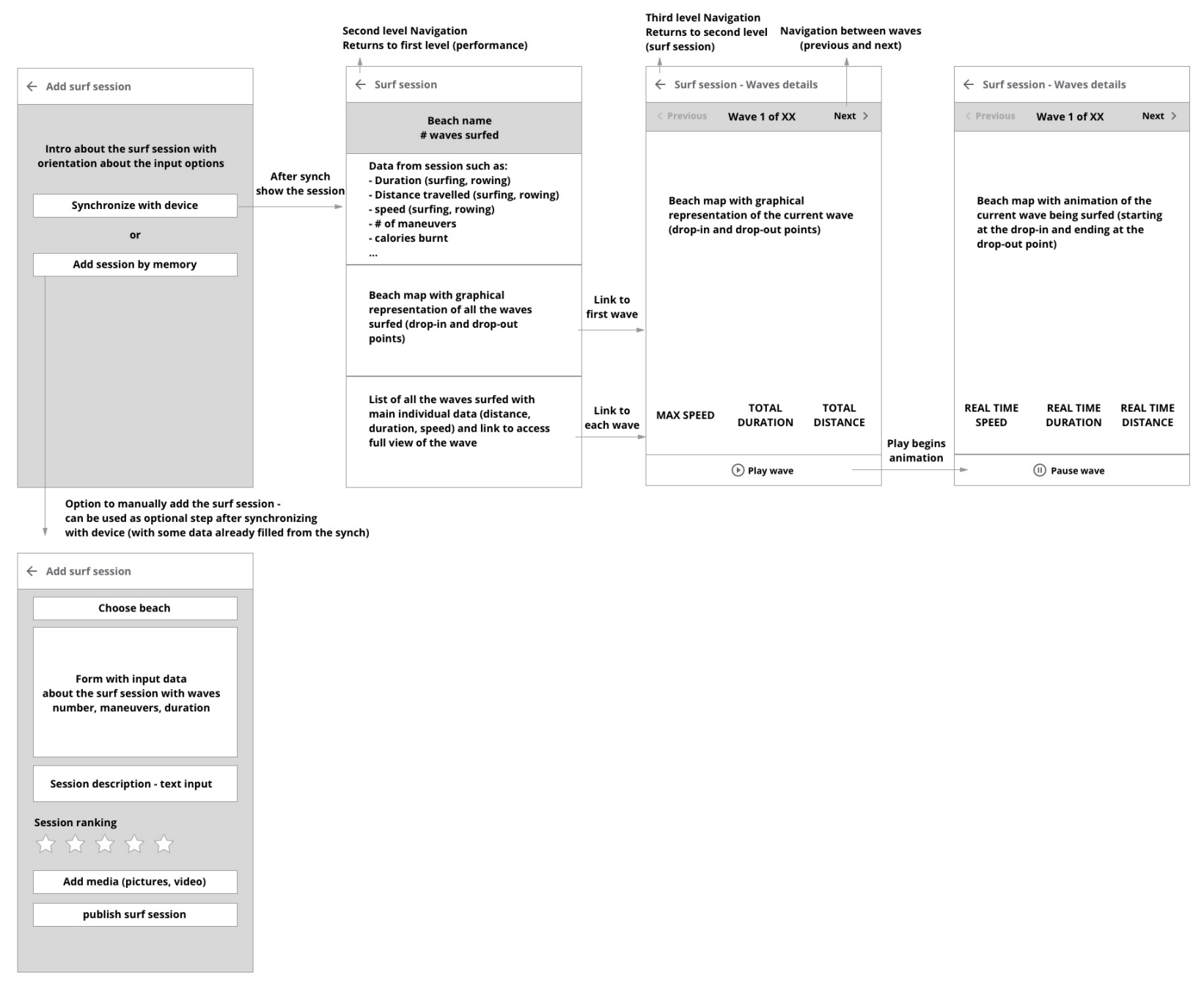

Figure 5. Surf session. Source: Elaborated by the author. 
be offered in the option "synchronise with device" after the data is transferred to the app as a way for the user to leave his session more complete: quantitative data tracked by the device with qualitative data entered by the user. The surf session result is composed of three parts, along with the name and number of surfed waves:

1. Surf session data, composed by data collected by the device and inserted by the user, fixed in all added sessions;

2. Graphical representation of the beach showing all surfed waves with its initial and ending points, available only on sessions tracked by the device;

3. List of all surfed waves with main individual data (duration, distance, speed) and link to access individual waves, available only on sessions tracked by the device.

When selecting to see each wave individually, the user has access to a graphical representation of the wave with the option to watch an animation created from the collected data, starting with the drop, surfing the wave and leaving or falling out. As the animation takes place, the wave data is shown dynamically as the surfer advances. An option to make the feature richer would be to allow the user to drag the starting point of the wave with his finger passing through each part until the end, with the wave data changing also according to the point that the user is focusing, analogous to scanning a video. Another option would be to show the animation zooming in the points of the wave to show the maneuvers executed, allowing a more detailed performance analysis capable of providing a graphic visualization of the quality of the maneuvers.

The result of the surf session has several development opportunities in order to make the performance analysis get a higher quality, but since it also represents more challenges in the development of the app, the suggestion for this feature is to start simple, focusing on the basic data of each wave, with a simpler visualization without animation and data changing dynamically, but in time could receive improvements to reach the point mentioned in the paragraph above. This serves to all features proposed in this app, always start developing a feature in a simple way to validate first with its users if it makes sense for your product and through a continuous improvement process with agile development, evolving the features as demand grows.

The systematic's goal is to help the development of this type of mobile app, offering validated results of the tools in the UCD process to make it faster without totally replacing it, due to the understanding that the results of the discovery and design phases are generic and can be used by anyone developing the same type of app. Still, the use of the process is critical to the development of a product centered on the user experience because even though there are many generic results, an essential part of the process is focused on specific business requirements, which cannot be generalized and are related to the company responsible for the development. Even the market requirements may change depending on the niche chosen, since the system does not have a specific niche, remaining on a level above that covers a large market for apps beyond surfing.

\section{Evaluation of the systematic and it's application}

For the evaluation of the systematic for sports performance tracking mobile apps in the UCD and its application in recreational surfing, a questionnaire was elaborated with questions regarding its applicability and contribution, applied to five professional experts in fields that contribute to the development of mobile apps in the area of sports with experience in recreational surfing. In addition to the questionnaire with closed questions, participants' comments were recorded. In relation to the questionnaire answered by the participants, Table 1 shows the notes of each of the evaluators for the questions.

The main opinions summarizing the evaluation of the application of the systematics are presented below:

It contributes greatly to the ecosystem, adding value to various actors. With the study generated, the applicability was demonstrated, as well as providing the necessary inputs, user-centered, for the software development market to initiate the development of a product (Evaluator 1).

The research and technical specifications presented are very well detailed and explained. I believe that for the development of a digital product the content is sufficient and understandable. To the market my impression is that people feel the need, but they would not invest heavily in it. So, my final assessment is that the product is interesting, well described, and possibly successful if it goes to the market (Evaluator 4).

I think it was well crafted and certainly contributes to the development of the app, since several searches have already been done and several data have been collected that will not be necessary to do it again when developing the app. The list of features was very objective and the proposed interface (GUI) was easy to understand (Evaluator 5).

In general, the evaluation results show that the requirements raised and the proposed solutions serve as a basis for companies and developers to use it in the development of apps aimed at tracking performance during recreational surfing. The averages of the last three questions related to the contribution in the development of this type of app, relevance of the presented information and contribution to develop products more centered in the user were all above $4(80 \%)$, demonstrating that the result reached its goal to contribute and present relevant data for its use as a reference 
Table 1. Evaluation of the professionals regarding applicability and contribution of the systematic application.

\begin{tabular}{|c|c|c|c|c|c|}
\hline What is you area of specialty? & $\begin{array}{l}\text { Business } \\
\text { analysis }\end{array}$ & $\begin{array}{l}\text { Physical } \\
\text { education }\end{array}$ & $\begin{array}{c}\text { Frontend } \\
\text { development }\end{array}$ & UX Design & $\begin{array}{c}\text { Backend } \\
\text { development }\end{array}$ \\
\hline $\begin{array}{l}\text { The user requirements are adequate for this type of } \\
\text { mobile app? }\end{array}$ & 5 & 3 & 3 & 5 & 4 \\
\hline The proposed solutions meet the user requirements? & 5 & 3 & 4 & 4 & 4 \\
\hline $\begin{array}{l}\text { The business requirements are adequate for this type } \\
\text { of mobile app? }\end{array}$ & 5 & 3 & 3 & 4 & 3 \\
\hline The proposed solutions meet the business requirements? & 5 & 3 & 4 & 4 & 3 \\
\hline $\begin{array}{l}\text { The market requirements are adequate for this type of } \\
\text { mobile app? }\end{array}$ & 5 & 3 & 4 & 4 & 3 \\
\hline The proposed solutions meet the market requirements? & 5 & 3 & 3 & 4 & 3 \\
\hline $\begin{array}{l}\text { The technological requirements are adequate for this } \\
\text { type of mobile app? }\end{array}$ & 5 & 3 & 4 & 3 & 4 \\
\hline $\begin{array}{l}\text { The proposed solutions meet the technological } \\
\text { requirements? }\end{array}$ & 5 & 3 & 4 & 3 & 3 \\
\hline $\begin{array}{l}\text { Contributes to the development of mobile apps for } \\
\text { surfers to track their performance? }\end{array}$ & 5 & 3 & 4 & 4 & 4 \\
\hline $\begin{array}{l}\text { The information presented in the systematic are } \\
\text { relevant to the development of this kind of mobile app? }\end{array}$ & 5 & 3 & 4 & 5 & 4 \\
\hline $\begin{array}{l}\text { Contributes to the development of more user centered } \\
\text { products of the type? }\end{array}$ & 5 & 5 & 4 & 5 & 5 \\
\hline
\end{tabular}

Source: Elaborated by the author.

system. The general opinions also reinforce this position, demonstrating its applicability and contribution. In relation to its application in surfing, the result was also positive through an average of over $4(80 \%)$ in the proposed user requirements raised and proposed solutions to meet those requirements. Considering that for a UX-centric mobile app the user requirements must be the main guiding principles of the design process, the application of the systematic has achieved a positive, user-centered result.

\section{Consolidation of the systematic}

After the application of the systematics and its evaluation, a review process was carried out to add relevant aspects of the user experience in sports, related to UX time intervals. Because it is a system for UX-focused sports performance tracking mobile apps, it was found that its construction is part of a system that unites a tracking device responsible for collecting data from the sports practice and the app responsible for analyzing and presenting to the user the data so that he can evolve his performance. This system requires an understanding of the entire UX context by using the user experience time intervals applied in the app and in the tracking device.

During the application of systematic in recreational surfing, a holistic approach was necessary to identify the entire context of use and not use. As the app itself does not produce the data it uses to analyze and present the user, it was necessary to include a device responsible for capturing the physiological and environmental variables that impact performance and consequently part of the user experience during sports practice. In this process of discovering the context of the total user experience, it was evident that the systematic should also address the system composed of the device and app. By dealing only with the app in isolation, the user experience would not be considered in its entirety, and could result in fragmented experiences within the device and app system, leading to a negative impact on the user.

The consolidation of this system took place through the study of the intervals of the UX in the sport, clarifying the periods of use of the device and the app that occur independently and also integrated. Using the periods "Preparing for Activity," "Performing Physical Activity," "Completing the Activity," and "Reflections and Actions to Improve Activities," it was clear the times when the app and the device could be used. The app plays an important role when the practitioner is preparing to perform the activity, after completing the activity and over time to reflect on his performance, while the device plays an important role in collecting data during sports practice with a period after the conclusion of the practice where both are used together, in the transfer of collected data from the device to the app.

\section{Conclusions}

The results obtained in the literature review on UX Design, UX Design in sports, UCD and surfing were sufficient for the construction of the systematic proposed, which proved useful, applicable and with contribution to this market. Thus, following the steps of the UCD, 
the systematic was proposed and applied in recreational surfing with the intention of serving as a reference in the development of mobile apps aimed at tracking surfers performance, focusing the user experience in the context of the practice of recreational surfing. The systematic proposal was the major contribution of this research, however, the results of the activities carried out during its application also contributes to exemplify the user-centered design process in the development of mobile apps to track performance in sports. The results showed that the UCD process is suitable for this purpose through the validation of the systematic and its application in recreational surfing by mobile app professionals, demonstrating their contribution and practical applicability.

During the construction of the systematic the initial focus was on the user-centered design process, seeking to identify the main phases involved, the activities performed in each phase and the tools and techniques used to carry out the activities. The focus on the process allowed to deepen in the main aspects to develop a mobile app focused on the user experience, through activities that put the user at the center of the software development. The first phase seeks to identify who the users are, how they perform the tasks related to current sports practice, what are the contexts of sports practice in their daily lives and what aspects of the experience related to performance are important for the user to evaluate and reflect to evolve in the sport . Raising this information is critical to building user, business, market, and technology requirements that serve as a foundation for devising solutions that address the problem of performance tracking, helping users in their primary pain, needs, and desires. In the second phase, solutions are created based on the requirements raised that will be specified to be developed in the third phase, while solutions are tested with users, entering an iterative cycle of continuous improvement, seeking to achieve a positive use experience with the mobile app.

After the construction of the systematic, its application in recreational surfing uncovered that although the design process was well elaborated, with adequate phases, activities, tools and techniques, the proposal lacked a visual demonstration of the system in which the app is part of. This was observed after some partial results in the discovery phase trying to apply the proposed tools. Therefore a holistic approach is essential for apps that have a physical counterpart responsible for collecting and analyzing the user's data, integrating both usage contexts. During the rest of the application, this was reinforced, directing the design process to a set of solutions focused on the total user experience within that system and not individually with the app or device. After the evaluation of the systematic, the proposal was reviewed, seeking to integrate the user experience intervals into the whole context of the sport practice, demonstrating which elements integrate the system responsible for tracking the practitioner's performance and how they interact in these intervals between themselves and independently.

\section{References}

AHTINEN, A. et al. Tracking outdoor sports - user experience perspective. In: AMBIENT INTELLIGENCE: PROCEEDINGS EUROPEAN CONFERENCE (AMI), 2008, Nuremberg. Proceedings... Berlin: Springer, 2008. p. 192-209.

AZEVEDO, L. S.; TOLEDO, J. C.; GONZÁLEZ, M. O. A. Understanding the interaction between actors in the productservice system development. Product: Management \& Development, v. 15 , n. 2 , p. $67-75,2017$. http://dx.doi. org/10.4322/pmd.2017.009.

BROWN, T. Design thinking. 2009. Available from: $<$ https:// designthinking.ideo.com/?page_id $=1542>$. Access on: 20 jun. 2017.

CASELLI, R. P. Análise de ferramentas para medição da experiência do usuário durante a prática esportiva de surfistas recreacionais. 2015. Total de páginas 99p [Aperfeiçoamento/Especialização em Especialização em UX Design]-Universidade Federal de Santa Catarina, Florianópolis, 2015.

DIAS, G. Nike trabalhará com a Apple no desenvolvimento de dispositivos vestíveis. TecMundo, 2014. Available from: <http://www.tecmundo.com.br/apple/64911-niketrabalhara-apple-desenvolvimento-dispositivos-vestiveis. htm>. Access on: 22 mai. 2014.

GABRIEL-PETIT, P. Design is a process, not a methodology. Ux Matters, 2010. Available from: <http://www.uxmatters. com/mt/archives/2010/07/design-is-a-process-not-amethodology.php>. Access on: 06 fev. 2017.

GUO, F. et al. An evaluation of wearable activity monitoring devices. In: MM'13 ACM MULTIMEDIA CONFERENCE: ACM INTERNATIONAL WORKSHOP ON PERSONAL DATA MEETS DISTRIBUTED MULTIMEDIA, 1., 2013, Barcelona. Proceedings... New York: ACM, 2013. p. 31-34.

HARTSON, R.; PYLA, P. S. The UX book: process and guidelines for ensuring a quality user experience. Waltham: MK, 2012.

HENRY, S. L.; THORP, J. Notes on User Centered Design Process (UCD). Cambridge: W3C, 2008. Available from: $<$ https://www.w3.org/WAI/redesign/ucd $>$. Access on: 15 jun. 2017.

INTERNATIONAL ORGANIZATION FOR STANDARDIZATION - ISO. 2010. ISO 9241: Ergonomics of human system interaction - Part 210: Human-centred design for interactive systems (formerly known as 13407). ISO 9241-210:2010(E). Switzerland. 
International Organization for Standardization (ISO), 2010. Available from: < http://www.iso.org/iso/catalogue_detail. htm?csnumber $=52075>$. Access on: 22 mai. 2015.

KARAPANOS, E. et al. Measuring the dynamics of remembered experience over time. Interacting with Computers, v. 22, n. 5, 2010, p. 328-335.

KOBAR, C. The UX design process. 2014. Available from: $<$ https://medium.com/@chriskobar/the-ux-design-process6e3935837520>. Access on: 22 jun. 2017.

LAW, E. L.-C. et al. Understanding, Scoping and Defining User eXperience: A Survey Approach. In: CHI '09 PROCEEDINGS OF THE SIGCHI CONFERENCE ON HUMAN FACTORS IN COMPUTING SYSTEMS, 9., 2009, Boston. Proceedings... New York: ACM, 2009. p. 719-728.

MYERS, B. A. A brief history of human computer interaction technology. Interactions, v. 5, n. 2, p. 44-54, 1998.

NYLANDER, S.; THOLANDER, J. Designing for movement: the case of sports. In: THE 2014 INTERNATIONAL WORKSHOP ON MOVEMENT AND COMPUTING, 2014, Paris. MOCO '14 Proceedings... New York: ACM, 2014. p. 130-135.

$\mathrm{OH}, \mathrm{J}$;; LEE, U. Exploring UX issues in quantified self technologies. In: PROCEEDINGS OF THE EIGHTH INTERNATIONAL CONFERENCE ON MOBILE COMPUTING AND UBIQUITOUS NETWORKING (ICMU), 2015, Hokadate. Proceedings... USA: IEEE, 2015. p. 53-59.

PILLONI, P. et al. Assessing the user experience design as a persuasive methodology in a real world sport application. In: INTERNATIONAL CONFERENCE ON
ADVANCES IN MOBILE COMPUTING \& MULTIMEDIA (MoMM '13), 2013, Vienna. Proceedings... New York: ACM, 2013. p. 387-394.

ROTO, V. et al. User experience white paper: bringing clarity to the concept of user experience. 2011. Available from: $<$ http://www.allaboutux.org/files/UX-WhitePaper.pdf $>$.

Access on: 16 jun. 2015.

SAHAR, F. et al. Identifying the user experience factors of a multi-component sports product. In: INTERNATIONAL ACADEMIC MINDTREK CONFERENCE, 2014, Tampere. Proceedings... New York: ACM, 2014. p. 87-94. Available from: <http://www.researchgate.net/profile/Farrukh_Sahar/ publication/267844082 Identifying the User Experience Factors_of_a_Multi-_Component_Sports_Product/ links/545b3b430cf2c16efbbbf0f7.pdf >. Access on: 16 jun. 2015.

SCHIFFMAN, L. G.; KANUK, L. L. Comportamento do consumidor. 9. ed. Rio de Janeiro: LTC, 2000. 445 p.

U.S. DEPARTMENT OF HEALTH \& HUMAN SERVICES. User-centered design process map. Washington, 2017. Available from: <https://www.usability.gov/how-to-andtools/resources/ucd-map.html>. Access on: 06 jun. 2017.

UX MASTERY. UX process. 2012. Available from: <https:// uxmastery.com/resources/process/>. Access in: 1 June 2017.

VARSALUOMA, J.; SAHAR, F. Usefulness of long-term user experience evaluation to product development: practioners' views from three case studies. In: PROCEEDINGS OF THE 8THNORDIC CONFERENCE ON HUMAN-COMPUTER INTERACTION: FUN, FAST, FOUNDATIONAL, 8., 2014, Helsinki. Proceedings... New York: ACM, 2014. p. $79-88$. 